\title{
Electromagnetic Phenomena Related to the 2011 Tohoku Earthquake and Tsunami: A Short Review
}

\author{
Stelios M Potirakis ${ }^{1,2 *}$, Alexander Schekotov ${ }^{3}$ and Masashi Hayakawa ${ }^{2,4}$ \\ ${ }^{1}$ Department of Electronics Engineering, Piraeus University of Applied Sciences, Greece \\ ${ }^{2}$ Hayakawa Institute of Seismo- Electromagnetics Co Ltd., Japan \\ ${ }^{3}$ Institute of Physics of the Earth, Russian Academy of Sciences, Russia \\ ${ }^{4}$ Advanced Wireless \& Communications research Center, University of Electro-Communications, Japan \\ *Corresponding author: Stelios M Potirakis, Department of Electronics Engineering, Piraeus University of Applied Sciences, Greece \\ Submission: 罡July 29, 2017 ; Published: 眥 November 13, 2017
}

\begin{abstract}
On March 11, 2011, a mega earthquake (magnitude-9.0) occurred off the Pacific coast of Tohoku, north central Japan, followed by a huge tsunami. In this short review, we present information about a variety of up to now published articles reporting different electromagnetic phenomena possibly related to the 2011 Tohoku earthquake or the associated tsunami. The reported anomalies are classified according to the type of electromagnetic phenomenon, while a timeline of occurrence is also provided.
\end{abstract}

Keywords: Tsunami; Earthquake; Pacific ocean; Geomagnetic field; Ionosphere; Seismo-electromagnetics

\section{Introduction}

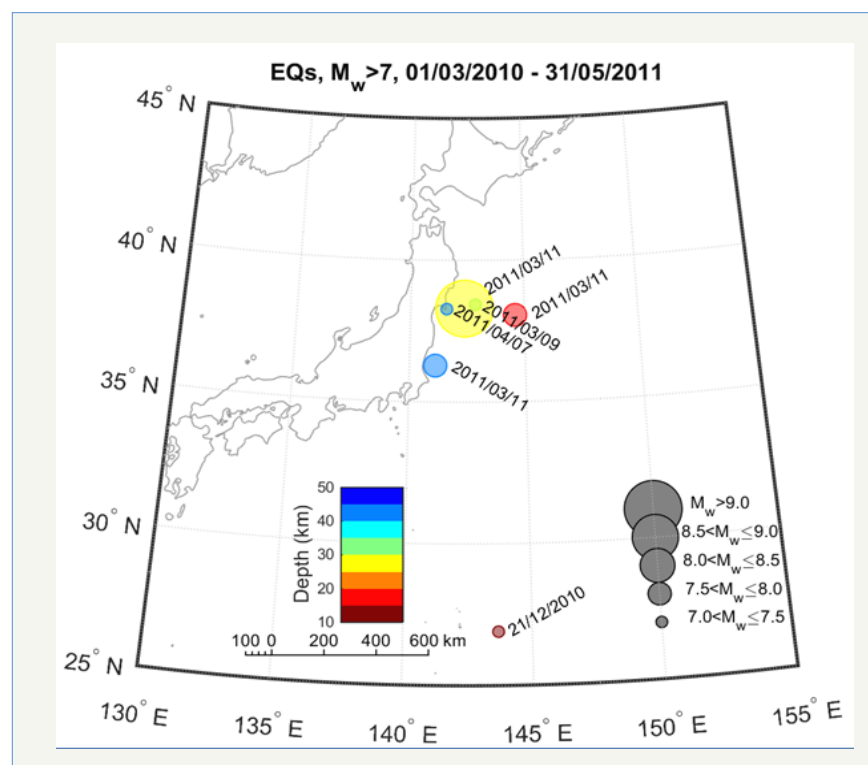

Figure 1: Map of the area of interest where the EQs of $M_{w}>7$ and depth less than $100 \mathrm{~km}$ which occurred from March 1 , 2010 to May31, 2011 are indicated by circles. The center of each circle is the corresponding EQ's epicenter, the size indicates its magnitude, and its color indicates the depth.

On March 11, 2011 a mega earthquake (EQ) of magnitude $=9.0$ took place at 14:46:18 JST $(\mathrm{UT}+9 \mathrm{~h})$ with its epicenter at the geographic coordinates $\left(38^{\circ} 06^{\prime} \mathrm{N}, 142^{\circ} 52^{\prime} \mathrm{E}\right.$ ) as shown by the larger circle in Figure 1. This was an oceanic EQ of the subduction type (mega thrust EQ) associated with the subduction of the Pacific plate along the Japan Trench. This EQ generated a huge tsunami that struck Japan as well as various locations around the Pacific Ocean, while the tsunami, apart from other damages, caused a cooling system failure at the Fukushima Daiichi nuclear power plant, which resulted in a level-7 nuclear meltdown and release of radioactive materials Mori etal. [1]. As a total 15,893 fatalities and 2,556 missing persons were recorded in different regions of Japan Fujii et al. [2], The National Police Agency [3], while the total material damages (infrastructures, company losses, personal properties, etc.) were of the order of $\sim \$ 300-\$ 450$ billion dollars Kazama \& Noda [4]. As it is logical, a large number of scientific articles investigating different aspects of these disastrous phenomena were written and are still being published. Different journals published special issues related to them Earth Planets \& Space [5,6], Bulletin of the Seismological Society of America [7], Science [8], while review articles with different focuses appear in the literature Okada et al. [9], Tajima et al. [10], Nagao et al. [11], Sato [12].

This short review is focused on presenting different electromagnetic (EM) phenomena possibly related to the Tohoku $\mathrm{EQ}$ and the subsequent tsunami which have been reported up to now. However, we have to mention that it is impossible to cite all of the publications. The classification followed in the text is based on 
the type of EM phenomenon, since for some observed EM anomalies there has been a dispute on whether they are related to the EQ or the tsunami, or have been attributed to both. Finally, a sorting of the EM anomalies discussed in this short review according to the timeline of their appearance, with regard to the time of Tohoku EQ occurrence, is provided in the summarizing Table 1.

Table 1:

\begin{tabular}{|c|c|c|c|c|}
\hline Occurrence time & Anomaly type & Method of identification & $\begin{array}{l}\text { Associated with } \\
\text { (EQ, tsunami) }\end{array}$ & Ref. \\
\hline$t_{0}-\sim 3 y, t_{0}-17 d$ & $\begin{array}{l}\text { DC / ULF geomagnetic field } \\
\text { components }\end{array}$ & $\begin{array}{l}\text { Ratio of thevertical component } \\
\text { difference to the horizontal component } \\
\text { difference }(\mathrm{dZ} / \mathrm{dH}) \text {; correlation of } \\
\text { magnetic field components between } \\
\text { stations }\end{array}$ & EQ & Kopytenko et al. [40] \\
\hline$\left(\mathrm{t}_{\mathrm{o}}-6 \mathrm{mo}, \mathrm{t}_{\mathrm{o}}-5 \mathrm{mo}\right)$ & $\begin{array}{l}\text { ULF geomagnetic field } \\
\text { components }\end{array}$ & $\begin{array}{l}\text { Detrended fluctuation analysis, Higuchi } \\
\text { fractal dimension, singular spectrum } \\
\text { analysis, correlation analysis }\end{array}$ & EQ & Potirakis et al. [46] \\
\hline $\mathrm{t}_{\mathrm{o}}-2 \mathrm{mo}$ & $\begin{array}{l}\text { DC geomagnetic field } \\
\text { components }\end{array}$ & $\begin{array}{l}\text { Ratios of diurnal variation range } \\
\text { between two stations, }\end{array}$ & EQ & $\mathrm{Xu}$ et al.[43] \\
\hline $\mathrm{t}_{\mathrm{o}}-2 \mathrm{mo}$ & $\begin{array}{l}\text { DC geomagnetic field } \\
\text { components }\end{array}$ & $\begin{array}{l}\text { Ratios of diurnal variation range } \\
\text { between two stations, wavelet } \\
\text { transform filtering of seasonal events }\end{array}$ & $\mathrm{EQ}$ & Han et al. [44] \\
\hline $\mathrm{t}_{\mathrm{o}}-2 \mathrm{mo}$ & $\begin{array}{l}\text { DC geomagnetic field } \\
\text { components }\end{array}$ & $\begin{array}{l}\text { Temporal-spatial analyses of } \\
\text { geomagnetic diurnal variation }\end{array}$ & $\mathrm{EQ}$ & Han et al. [45] \\
\hline$\left[\mathrm{t}_{\mathrm{o}}-14 \mathrm{~d}, \mathrm{t}_{\mathrm{o}}-12 \mathrm{~d}\right]$ & $\begin{array}{l}\text { Monitoring of EM signals } \\
\text { of lightning discharges } \\
\text { (atmospherics) }\end{array}$ & Lightning location methods & $\mathrm{EQ}$ & Mullayarov et al. [34] \\
\hline$\left[\mathrm{t}_{\mathrm{o}}-10 \mathrm{~d}, \mathrm{t}_{\mathrm{o}}-5 \mathrm{~d}\right]$ & $\begin{array}{l}\text { Monitoring subionospheric } \\
\text { VLF/LF propagation }\end{array}$ & Statistical analysis & EQ & Hayakawa et al. [30-32] \\
\hline $\begin{array}{l}{\left[\mathrm{t}_{\mathrm{o}}-10 \mathrm{~d}, \mathrm{t}_{\mathrm{o}}-1 \mathrm{~d}\right]\left(\max :\left[\mathrm{t}_{\mathrm{o}}-\right.\right.} \\
\left.\left.3 \mathrm{~d}, \mathrm{t}_{\mathrm{o}}-1 \mathrm{~d}\right]\right)\end{array}$ & $\begin{array}{l}\text { Ionospheric total electron } \\
\text { content (GPS-TEC) }\end{array}$ & $\begin{array}{l}\text { Mean, median, wavelet transform, and } \\
\text { Kalman filter }\end{array}$ & $\mathrm{EQ}$ & Akhoondzadeh [15] \\
\hline$\left[\mathrm{t}_{\mathrm{o}}-8 \mathrm{~d}, \mathrm{t}_{\mathrm{o}}\right]$ & $\begin{array}{l}\text { OLR, GPS/TEC, lower } \\
\text { Earth orbit ionospheric } \\
\text { tomography and critical } \\
\text { frequency foF2 }\end{array}$ & $\begin{array}{l}\text { Joint analysis of atmospheric and } \\
\text { ionospheric parameters }\end{array}$ & $\mathrm{EQ}$ & Ouzounov et al. [37] \\
\hline $\begin{array}{c}{\left[\mathrm{t}_{0}-8 \mathrm{~d}, \mathrm{t}_{0}-6 \mathrm{~d}\right], \mathrm{t}_{0}-5 \mathrm{~d}} \\
\mathrm{t}_{0}-4 \mathrm{~d}\end{array}$ & $\begin{array}{l}\text { ULF geomagnetic field } \\
\text { components }\end{array}$ & Natural time analysis & EQ & Hayakawa et al. [47] \\
\hline $\mathrm{t}_{\mathrm{o}}-8 \mathrm{~d}, \mathrm{t}_{\mathrm{o}}-7 \mathrm{~d}, \mathrm{t}_{\mathrm{o}}-5 \mathrm{~d}$ & $\begin{array}{l}\text { ULF geomagnetic field } \\
\text { components }\end{array}$ & Method of critical fluctuations & EQ & Contoyiannis et al. [48] \\
\hline $\begin{array}{c}\mathrm{t}_{\mathrm{o}}-6 \mathrm{~d}, \mathrm{t}_{\mathrm{o}}-3 \mathrm{~d}, \mathrm{t}_{\mathrm{o}}(\max : \\
\left.\mathrm{t}_{\mathrm{o}}-3 \mathrm{~d}\right)\end{array}$ & $\begin{array}{l}\text { Ionospheric total electron } \\
\text { content (GPS-TEC) }\end{array}$ & $\begin{array}{l}\text { Difference in the diurnal TEC } \\
\text { between the estimated GPS- TEC } \\
\text { for } 20 \text { consecutive days in March, } \\
2011 \text { and the median GPS-TEC for } \\
\text { the geomagnetically quiet } 7 \text { days in } \\
\text { February } 2011\end{array}$ & $\mathrm{EQ}$ & Choi et al. [16] \\
\hline$\left[\mathrm{t}_{0}-6 \mathrm{~d}, \mathrm{t}_{\mathrm{o}}-5 \mathrm{~d}\right]$ & $\begin{array}{c}\text { ULF magnetic field } \\
\text { depression as monitored } \\
\text { by ground-based magnetic } \\
\text { observatories }\end{array}$ & Statistical analysis & $\mathrm{EQ}$ & Hayakawa et al. [33] \\
\hline$t_{0}-5 d$ & $\begin{array}{l}\text { NS and EW horizontal } \\
\text { components of the ULF/ELF } \\
\text { geomagnetic field }\end{array}$ & $\begin{array}{l}\text { Detection of seismo-atmospheric EM } \\
\text { radiation and determination of the } \\
\text { azimuth of its source }\end{array}$ & $\mathrm{EQ}$ & Ohta et al. [42] \\
\hline$t_{0}-3 d$ & $\begin{array}{l}\text { Ionospheric total electron } \\
\text { content (GPS-TEC) }\end{array}$ & $\begin{array}{l}\text { Comparison of measurements with } \\
\text { different models }\end{array}$ & EQ & Le et al. [17] \\
\hline$t_{0}-1 h$ & $\begin{array}{c}\text { Ionosonde data, peak } \\
\text { plasma frequencies of the } \\
\text { F2 and Es layers (foF2, foEs) }\end{array}$ & $\begin{array}{l}\text { Running 30-day median, the } \\
\text { International Reference Ionosphere } \\
\text { (IRI) model and the Thermosphere } \\
\text { Ionosphere Electrodynamic General } \\
\text { Circulation Model (TIE-GCM). }\end{array}$ & EQ & Carter et al. [26] \\
\hline$t_{0}-40 \min$ & $\begin{array}{l}\text { Ionospheric total electron } \\
\text { content (GPS-TEC) }\end{array}$ & $\begin{array}{l}\text { Comparison of slant TEC change with } \\
\text { models extracted using data of the EQ } \\
\text { day (excluding the data of the anomaly } \\
\text { period) }\end{array}$ & $\mathrm{EQ}$ & Heki [14] \\
\hline
\end{tabular}




\begin{tabular}{|c|c|c|c|c|}
\hline $\mathrm{t}_{\mathrm{o}}-40 \mathrm{~min}$ & $\begin{array}{l}\text { Ionospheric total electron } \\
\text { content (GPS-TEC) }\end{array}$ & $\begin{array}{l}\text { Commenting on Kamogawa \& Kakinami } \\
\text { [19] and presenting two methods for } \\
\text { validating Heki [14] results }\end{array}$ & $\mathrm{EQ}$ & $\begin{array}{l}\text { Heki K, and Enomoto } \mathrm{Y} \\
{[20]}\end{array}$ \\
\hline $\mathrm{t}_{\mathrm{o}}-40 \mathrm{~min}$ & $\begin{array}{l}\text { Ionospheric total electron } \\
\text { content (GPS-TEC) }\end{array}$ & Commenting on Utada \& Shimizu [21] & $\mathrm{EQ}$ & Heki and Enomoto [22] \\
\hline$t_{0}-40 \min$ & $\begin{array}{l}\text { Ionospheric total electron } \\
\text { content (GPS-TEC) }\end{array}$ & Simulation & $\mathrm{EQ}$ & Kuo et al. [23] \\
\hline $\mathrm{t}_{\mathrm{o}}($ coseismic $)$ & $\begin{array}{l}\text { DC geomagnetic total } \\
\text { intensity }\end{array}$ & $\begin{array}{l}\text { Time series values after correcting } \\
\text { the effect of external disturbances and } \\
\text { induced fields }\end{array}$ & $\mathrm{EQ}$ & Utada et al. [39] \\
\hline$\left[\mathrm{t}_{\mathrm{o}}, \mathrm{t}_{\mathrm{o}}+1 \mathrm{~h}\right]$ & $\begin{array}{l}\text { DC geomagnetic field total } \\
\text { intensity }\end{array}$ & $\begin{array}{l}\text { Time series values after correcting } \\
\text { the effect of external disturbances and } \\
\text { induced fields }\end{array}$ & tsunami & Utada et al. [39] \\
\hline$\left[\mathrm{t}_{\mathrm{o}}, \mathrm{t}_{\mathrm{o}}+1 \mathrm{~h}\right]$ & $\begin{array}{l}\text { DC geomagnetic field } \\
\text { components }\end{array}$ & $\begin{array}{l}\text { Spectrum analysis, Rayleigh wave } \\
\text { model of seismo-ionospheric } \\
\text { disturbances }\end{array}$ & $\mathrm{EQ}$ and tsunami & Hao et al. [41] \\
\hline $\mathrm{t}_{\mathrm{o}}+7 \mathrm{~min}$ & $\begin{array}{l}\text { Ionospheric total electron } \\
\text { content (GPS-TEC) }\end{array}$ & Band - pass filtered GPS - TEC & $\mathrm{EQ}$ and tsunami & Liu et al. [13] \\
\hline$t_{0}+9 \min$ & $\begin{array}{l}\text { Continuous Doppler } \\
\text { sounding system }\end{array}$ & $\begin{array}{l}\text { Doppler shift spectrograms, } \\
\text { comparison with models }\end{array}$ & EQ & Chum et al. [29] \\
\hline$\left[\mathrm{t}_{\mathrm{o}}+10 \mathrm{~min}, \mathrm{t}_{\mathrm{o}}+80 \mathrm{~min}\right]$ & $\begin{array}{l}\text { Ocean-bottom } \\
\text { electromagnetometer }\end{array}$ & $\begin{array}{l}\text { Analysis of magnetic field components } \\
\text { and offshore sea-level data }\end{array}$ & tsunami & Ichihara et al. [51] \\
\hline $\mathrm{t}_{\mathrm{o}}+15 \min$ & $\begin{array}{l}\text { Ionospheric total electron } \\
\text { content (GPS-TEC) }\end{array}$ & $\begin{array}{l}\text { Comparison of slant TEC change with } \\
\text { models extracted using data on the } \\
\text { similar GPS satellite orbit on a day } \\
\text { other than the EQ day. }\end{array}$ & tsunami & Kakinami et al. [18] \\
\hline $\mathrm{t}_{\mathrm{o}}+15 \mathrm{~min}$ & $\begin{array}{l}\text { Ionospheric total electron } \\
\text { content (GPS-TEC) }\end{array}$ & $\begin{array}{l}\text { Commenting on Heki[14] \& Kakinami } \\
\text { et al. [18] results }\end{array}$ & tsunami & $\begin{array}{c}\text { Kamogawa \& Kakinami } \\
{[19]}\end{array}$ \\
\hline$t_{0}+15 \min$ & $\begin{array}{l}\text { Ionospheric total electron } \\
\text { content (GPS-TEC) }\end{array}$ & Simulation & tsunami & Shinagawa et al. [25] \\
\hline $\mathrm{t}_{\mathrm{o}}+15 \mathrm{~min}$ & $\begin{array}{l}\text { Ionospheric total electron } \\
\text { content (GPS-TEC) }\end{array}$ & $\begin{array}{c}\text { Commenting on Heki, K., \& Enomoto, } \\
\text { Y. [20] }\end{array}$ & tsunami & Utada \& Shimizu [21] \\
\hline$t_{0}+15 \min$ & $\begin{array}{c}\text { Ionosonde data, peak } \\
\text { plasma frequency of the F2 } \\
\text { layer (foF2) }\end{array}$ & $\begin{array}{l}\text { Height derivative of the plasma } \\
\text { frequency as a function of time and } \\
\text { height and other methods }\end{array}$ & $\mathrm{EQ}$ & Berngardt et al. [27] \\
\hline$\left[\mathrm{t}_{\mathrm{o}}+15 \mathrm{~min}, \mathrm{t}_{\mathrm{o}}+30 \mathrm{~min}\right]$ & $\begin{array}{l}\text { Ionosonde data, peak } \\
\text { plasma frequency of the } \\
\text { F1,F2, and Es layers (foF1, } \\
\text { foF2, foEs) }\end{array}$ & $\begin{array}{c}\text { Simulation, comparison with } \\
\text { seismograms }\end{array}$ & $\mathrm{EQ}$ & $\begin{array}{c}\text { Maruyama \& Shinagawa } \\
{[28]}\end{array}$ \\
\hline to $+1 \mathrm{~h}$ & $\begin{array}{l}\text { Ionospheric total electron } \\
\text { content (GPS-TEC) }\end{array}$ & $\begin{array}{l}\text { Analytical description and } \\
\text { measurement data }\end{array}$ & tsunami & Occhipinti et al. [24] \\
\hline$\left[\mathrm{t}_{\mathrm{o}}+60 \mathrm{~min}, \mathrm{t}_{\mathrm{o}}+80 \mathrm{~min}\right]$ & $\begin{array}{l}\text { Ocean-bottom } \\
\text { electromagnetometer }\end{array}$ & Several analysis methods & tsunami & Zhang et al. [52] \\
\hline $\mathrm{t}_{\mathrm{o}}+\sim 1 \mathrm{~h}$ & $\begin{array}{l}\text { Vertical component (Z) of } \\
\text { the DC geomagnetic field }\end{array}$ & $\begin{array}{l}\text { Comparison of magnetic field and sea- } \\
\text { level changes, simulation }\end{array}$ & tsunami & Tatehata et al. [49] \\
\hline $\mathrm{t}_{\mathrm{o}}+\sim 1 \mathrm{~h}$ & $\begin{array}{l}\text { Vertical component }(\mathrm{Z}) \text { of } \\
\text { the DC geomagnetic field }\end{array}$ & $\begin{array}{l}\text { Travel time diagram of the magnetic } \\
\text { disturbances, correlation analysis }\end{array}$ & tsunami & Klausner et al. [50] \\
\hline$\left[\mathrm{t}_{\mathrm{o}}+1 \mathrm{~h}, \mathrm{t}_{\mathrm{o}}+1.5 \mathrm{~h}\right]$ & $\begin{array}{l}\text { Monitoring subionospheric } \\
\text { VLF/LF propagation }\end{array}$ & Statistical analysis & tsunami & Rozhnoi et al. [35] \\
\hline$t_{0}+1.5 h$ & $\begin{array}{l}\text { Monitoring subionospheric } \\
\text { VLF/LF propagation }\end{array}$ & $\begin{array}{l}\text { Statistical analysis, comparison to the } \\
\text { in-situ sea-level GPS measurements }\end{array}$ & tsunami & Rozhnoi et al. [36] \\
\hline $\mathrm{t}_{\mathrm{o}}+2.33 \mathrm{~h}$ & $\begin{array}{l}\text { Doppler shift } \\
\text { measurements, GPS/TEC, } \\
\text { magnetic field }\end{array}$ & multi-instrument-based study & $\mathrm{EQ}$ and tsunami & Hao et al. [38] \\
\hline
\end{tabular}




\section{Ionosphere anomalies}

Different kinds of ionosphere anomalies have been reported to be related, or have been investigated for possible relation, with the 2011 Tohoku EQ and/or tsunami. These include ionosphere total electron content (TEC) anomalies, infrasonic waves, disturbances of peak plasma frequencies of different layers, ultra-low frequency (ULF) magnetic field depression, and very-low/low (VLF/LF) lower ionosphereric perturbation. Specific articles concerning each one of these categories are briefly discussed in the following.

\section{GPS-TEC anomalies}

Liu et al. [13] reported TEC anomalies derived from nationwide global positioning system (GPS) receiving networks in Japan and Taiwan, attributing them to the traveling of Earth surface and tsunami motions up to the ionosphere. The first anomalies observed by Liu et al. [13] appeared as a disk - shaped TEC increase about $7 \mathrm{~min}$ after the EQ occurrence. Heki [14] reported that the Japanese network of GPS detected a precursory positive TEC anomaly around the focal region, which started $\sim 40$ minutes before the Tohoku EQ and reached nearly ten percent of the background TEC, while it lasted until atmospheric waves arrived at the ionosphere. The method used was a comparison of slant TEC change with TEC models Heki [14]. A precursor to the Tohoku EQ was also reported by Akhoondzadeh [15] who using four methods, mean, median, wavelet transform, and Kalman filter, detected a considerable number of anomalous occurrences during 1 to 10 days prior to the EQ. The highest deviations from the normal state that were regarded as anomaly appeared within the time interval 1-3 days before the EQ. Based on measurements of the GPS network of on the Korean Peninsula, Choi et al. [16] detected ionosphere TEC anomalies during the daytime. Specifically, they reported that an increase in TEC appeared on March 5, 8 and 11, while the March 8 ones were remarkable Le et al. [17] also reported a significant enhancement in TEC on March 8, 2011, probably related to the Tohoku EQ. Yet, they suggest that the detected anomalies may also be contributed partly by the geomagnetic disturbance $(\mathrm{Kp}=4)$ which occurred on March 7.

Moreover, Kakinami et al. [18] were focusing on the so-called "tsunamigenic ionospheric hole", which is a sudden depletion of ionospheric TEC in the hundred kilometer scale and lasts for a few tens of minutes over the tsunami source area. They concluded that this kind of phenomenon appears only in cases of large EQs followed by tsunamis and not in the case of inland large EQs. Then, Kamogawa \& Kakinami [19] commented on Heki [14] findings compared with those of Kakinami et al. [18] suggesting that the anomaly reported by Heki [14] is a false one resulted by inappropriate model reference. The difference between Heki [14] and Kakinami et al. [18] is attributed to the reference curves of the TEC to extract the ionosphere variations. The former is given by the least-squares fitting curve of the EQ day data excluding an expected precursor period, while the latter is given by the data of the similar orbit of GPS satellite on another day. Later, Heki \& Enomoto [20] published a rebuttal to this by employing two new methods for the validation of Heki [14] findings, while Utada \& Shimizu [21] further investigated this issue by concluding that the observation of anomalous declination changes before the Tohoku EQ does not confirm the reality of the precursory TEC enhancement. Finally, Heki \& Enomoto [22] questioned part of the conclusions of Utada \& Shimizu [21] regarding the validity of the Heki [14] precursor, concluding though that the relation between geomagnetic variations and TEC disturbances should be further investigated in the future. Kuo et al. [23] applied their improved lithosphereatmosphere-ionosphere (LAI) coupling model to compute the TEC variations and compare the simulation results with the Heki [14] reported TEC observations related to Tohoku EQ and determined the necessary conditions in order for the reported anomaly to be reproduced by the specific model.

Referring to data from Tohoku EQ but also other tsunamigenic EQs, Occhipinti et al. [24] deal with the discrimination of TEC anomalies related to the acoustic-gravity waves generated at the epicenter by the direct vertical displacement of the source rupture and those related to the gravity wave coupled with the tsunami. They used an analytical (theoretical) description of the involved phenomena for this purpose.Also based on the TEC anomalies observed after the Tohoku EQ, Shinagawa et al. [25] proceeded with a simulation study based on a two-dimensional nonlinear non hydrostatic compressible atmosphere-ionosphere model. They concluded that an impulsive pressure pulse produced by a sudden uplift of the sea surface leads to local atmospheric expansion in the thermosphere and that the expansion of the thermosphere combined with the effect of inclined magnetic field lines in the ionosphere causes the sudden TEC depletion above the epicenter region.

\section{Peak plasma frequency anomalies and infrasound waves}

Before the TohokuEQ, an anomaly in the peakplasma frequencies of the F2 layer (foF2) and the Es layer (foEs) was reported by Carter et al. [26]. By using ionosonde data and three separate baselines for foF2, the running 30-day median, the International Reference Ionosphere (IRI) model and the Thermosphere Ionosphere Electrodynamic General Circulation Model (TIE-GCM), they found that a simultaneous increase in foF2 and foEs relative to the 30day median happened within $1 \mathrm{~h}$ before the EQ. However, in lack of statistical evidence, they concluded that one cannot confidently use this type of ionospheric perturbation to predict an impending EQ. On the other hand, Berngardt et al. [27] studied the dynamics of vertical ionospheric irregularities caused by Tohoku EQ based on the data obtained from Irkutsk CHIRP ionosonde, at $3400 \mathrm{~km}$ distance from the EQepicenter. They concluded that the identified irregularities, 06:00 to 06:20 UT, are qualitatively explained by traveling of the acoustic shock wave cone.

Strong deformation of ionogram echo traces, forming multiple cusp signatures (MCSs), were observed at three stations 790$1880 \mathrm{~km}$ from the epicenter Maruyama \& Shinagawa [28]. It was concluded that the travel time diagram of the seismic records along the line connecting the epicenter and ionosondes showed that the 
rest MCS ionogram detected at each station was caused by P waves, while the others were caused by Rayleigh waves. A train of large amplitude infrasound wave packets was observed by multipoint continuous Doppler sounding system in the ionosphere over the Czech Republic on March 11, 2011. Chum et al. [29] showed that these infrasound wave packets originated from vertical motion of the ground surface that was caused by arrival of seismic waves generated by the strong Tohoku EQ.

\section{Lower ionosphere disturbances}

By using the network observations of sub-ionospheric VLF/ LF signals in Japan and Russia, Hayakawa et al. [30,31] found a significant ionospheric perturbation prior to the Tohoku EQ Specifically, a remarkable decrease was detected in the nighttime amplitude and increase in the dispersion on March 5 and 6, on the paths from NLK (Seattle, USA) to Chofu, Kochi and Kasugai, while anomalies were also found in March 1-6 period and minima in the nighttime amplitude on March 3 and 4 on the path JJI (Miyazaki, Kyushu) - Kamchatka, Russia. Moreover, different aspects of the observed phenomenon, the possible relation with other phenomena, the existence of similar perturbations and a possible generation mechanism were extensively investigated in Hayakawa et al. [32].

Additionally, another phenomenon reflecting sub-ionospheric perturbations, the depression of the magnetospheric ULF emissions observed on ground-based stations was reported by Hayakawa et al. [33] as a possible precursor to the Tohoku EQ. Clear depression of the ULF magnetic field happened on March 5 and 6, during a period that VLF/LF propagation anomaly was also found. The monitoring of lower ionosphere disturbances by means of detection of natural radio emissions, i.e. EM signals of lightning discharges (atmospherics) also revealed possible precursors of the Tohoku EQ and a M7.3 EQ which happened very close to it two days before, as well disturbances after Tohoku EQ Mullayarov et al. [34].

Finally, tsunami-induced subionospheric anomalies (both in the amplitude and phase) have also been reported after the Tohoku EQ and tsunami by means of VLF/LF propagation monitoring Rozhnoi et al. $[35,36]$ The observed effects in the ionosphere were compared to the in-situ sea-level GPS measurements near Japan Rozhnoi et al. [36], while a qualitative interpretation of the observed effects was suggested in terms of the interaction of internal gravity waves with lower ionosphere Rozhnoi et al. [35].

\section{Multi-instrument revealed anomalies}

Ouzounov et al. [37] retrospectively analyzed the temporal and spatial variations of four different physical parameters characterizing the state of the atmosphere and ionosphere several days before the Tohoku EQ. They used outgoing long wave radiation (OLR), GPS/TEC, lower Earth orbit ionospheric tomography and critical frequency foF2 data and found different kinds of anomalies in the time period March 3 to 11, 2011. Moreover, in a multiinstrument-based study, Hao et al. [38] observed in Beijing, by a local infrasound detector, surface-oscillation-excited ionospheric anomalies related to the Tohoku EQ. The ionosphere disturbances were detected by HF Doppler shift measurements as well as by fluctuations of GPS/TEC. They also suggested that interactions between the electron density variation and ionospheric current were manifested by geomagnetic field is turbines measured by ground-based magnetometers. Hao et al. [38] reported that infrasonic waves excited around the epicenter or tsunami area propagated horizontally in the atmosphere and were received by the infrasound detector in Beijing $2 \mathrm{~h}$ and 20 min later at a distance of about 2400-2500 km from their source region.

\section{Geomagnetic field anomalies}

The possible relation of magnetic anomalies recorded by ground-based or sea-bottom magnetic observatories with the 2011 Tohoku EQ and/or tsunami, has been extensively investigated. Specific articles concerning each one of these categories are briefly discussed in the following.

\section{Ground-based magnetic field anomalies}

Simultaneous measurements of the geomagnetic field in association with the Tohoku EQ and tsunami by magnetometers at 14 stations operating in Japan were reported by Utada [39]. They found a coseismic change of the main geomagnetic field (DC geomagnetic field) observed at several stations located relatively close to the epicenter. Moreover, they reported distinct and rapid changes during the hours following the main shock attributed either to the motional induction of the tsunami or to ionospheric disturbance.

Kopytenko et al. [40] reported that disturbances both in the main magnetic field of the Earth and in ULF geomagnetic field variations $(\mathrm{f}<10 \mathrm{~Hz})$ were observed before the Tohoku EQ. Secular variations of the main geomagnetic field were investigated using three-component 1-h data from three magnetic observatories over the 11-year period of January 1, 2000, to January 31, 2011. They used data from the Esashi and Mizusawa magnetic stations (situated northwest of the EQ epicenter, at distances $\sim 170 \mathrm{~km}$ to $200 \mathrm{~km}$ ), as well as from the Kakioka observatory (situated southwest of the EQ epicenter, at a distance of $\sim 300 \mathrm{~km}$ ). During this period, they found four local anomalies in the secular variations, the last of which (the biggest) began around 3 years prior to the EQ. Concerning the ULF magnetic field variations, they analyzed three-component 1-s data at two magnetic stations (Kakioka and Uchiura).

The Uchiura station is situated south to Kakioka, at a distance of $\sim 420 \mathrm{~km}$ from the EQ epicenter. They found that a decrease in the correlation coefficients of the corresponding magnetic components at these two stations happened from February 22, 2011. Differences in the $\mathrm{Z}$ components showed an increase, and became positive after this date. They concluded that this might suggest that the ULF lithospheric source appeared north of the Kakioka station. Anomalous magnetic variations, teleseismic magnetic effects (TMDs), due to the Tohoku EQ were reported by Hao et al. [41] which were still notable at stations $2000-4000 \mathrm{~km}$ away from the epicenter. They suggested that these TMDs were not generated by 
direct effects of processes in the focal area crust or tsunami waves; instead, their properties consisted with the Rayleigh wave model of seismo-ionosphere disturbances. They suggested that these were the magnetic manifestation of seismo traveling ionospheric disturbances (STIDs) generated by the interaction between the ionosphere and atmosphere through acoustic waves launched by traveling Rayleigh waves.

The ULF/ELF short-term EM precursor was reported by Ohta et al. [42] that was identified 5 days before the Tohoku EQ, using data from search coil magnetometers of the Chubu University network. A confirmation on its seismic origin was provided by the observational fact that the azimuths of the radiation source from all observation sites coincided approximately with the region of the forthcoming EQ. Moreover, the unusual behavior of geomagnetic diurnal variations 2 months prior to the Tohoku EQ were reported by $\mathrm{Xu}$ et al. [43] by calculating ratios of diurnal variation range between the target station Esashi (ESA), 135km from the epicenter, and the remote reference station Kakioka (KAK), $302 \mathrm{~km}$ from the epicenter. The original records of geomagnetic fields of the ESA station also exhibited continuous anomalous behavior for about 10 days in the vertical component $\sim 2$ months prior to the EQ.

The study of the geomagnetic diurnal variations anomaly related to the Tohoku EQ was further investigated by Han et al. [44] by analyzing geomagnetic data of 16 years' long term observation. They found that, after removing seasonal variations revealed by wavelet transform analysis, the 15-day mean values of the ratios in the vertical component shows a clear anomaly exceeding the statistical threshold about 2 months before the mega event. The investigation of geomagnetic diurnal variation anomaly prior to the Tohoku EQ was further extended to temporal-spatial analysis of long-term observations at 17 stations in Japan by Han et al. [45]. Their analysis ended-up to the same results about the time of occurrence of the precursory behavior. Moreover, the locations of anomalies in spatial distribution showed a good correlation with the epicenter of the Tohoku EQ, while the obtained spatiotemporal results were found to be consistent with those obtained from other independent observations such as groundwater level and GPS displacements.

Furthermore, a fractal analysis of the ULF magnetic field variations prior to the Tohoku EQ with the use of detrended fluctuation analysis (DFA) and Higuchi fractal dimension algorithm was presented by Potirakis et al. [46], aiming at discriminating between possible EQ precursors from space-sourced disturbances. Fractal analysis results revealed a change in fractal characteristics, namely a gradual reduction in DFA a-exponent values and corresponding gradual increase in Higuchi fractal dimension values, 5-6 months before the Tohoku EQ. The observed changes were recovered after the occurrence of the EQ. The extensive filtering and correlation analyses performed suggest, according to the authors, that the observed disturbance was locally driven sourced at the EQ preparation processes and not related to spacesourced disturbances.
By applying natural time (NT) analysis on daily values of ULF magnetic field characteristics calculated on the basis of the magnetic field components' power during low noise nighttime intervals, Hayakawa et al. [47] found that criticality features appear in the geomagnetic field variations 8-6, 5 and 4 days prior to the Tohoku EQ occurrence. They suggested that these findings reflect the critical condition reached by the lithosphere, either as embedded into direct emissions (8-6 days before the EQ) or as embedded in the geomagnetic signature (horizontal field depression) of ionosphere disturbance ( 5 and 4 days before the EQ).The critical behavior of ULF magnetic field variations was further verified by Contoyiannis et al. [48] after applying a completely different analysis method, the method of critical fluctuations (MCF), on the raw magnetic field recordings. Specifically, they found clear signatures of intermittent criticality in the recordings of 4 March 2011, while indications of critical behavior were also found in 3 and 6 March recordings, although not of the "stability" of those of 4 March. Moreover, it was found that only the ULF data of the geomagnetic observatory nearest to the EQ epicenter presented criticality. This finding further corroborates the view that the presented signal is indeed a precursor to the specific EQ.

Beginning from the fact that the vertical component of the magnetic field at Chichijima Island, $1200 \mathrm{~km}$ south of the epicenter of Tohoku EQ presented a periodic signal at approximately 20 min before the tsunami arrived, Tatehata et al. [49] compared the sea-level changes and magnetic field variations after the EQ. Furthermore, using a simulation, they investigated the mechanism producing the observed magnetic field signal and tried to confirm that the oceanic dynamo effect caused the magnetic field variations. They found that the vertical component of the geomagnetic field and the tide gauge records at Chichijima Island exhibited very similar patterns. Moreover, they concluded that the straight-line electric current induced a secondary magnetic field that curled at the front of the first tsunami wave.

Klausner et al. [50] examined the effects of Tohoku EQ tsunami to the vertical component $(\mathrm{Z})$ of the geomagnetic field observed by 9 ground-based observatories distributed along the tsunami passage, covering up to $3000 \mathrm{~km}$ epicentral distance. They identified the amplified magnetic disturbances appearing during the tsunami arrival in the vicinity of the specific observatories and examined the cross correlations among different observatories and the amplified disturbances. These were found to be highly correlated, concluding that this result suggests that the observed magnetic field disturbances were tsunamigenic.

\section{Sea-bottom magnetic field anomalies}

A tsunami induces secondary EM fields of significant intensity as a result of Faraday 's law, and these EM fields can be recorded by instruments on the sea floor. Tsunami-induced magnetic signals related to the tsunami triggered by the Tohoku EQ from an oceanbottom electro magnetometer emplaced $50 \mathrm{~km}$ east of the Japan Trench were reported by Ichihara et al. [51]. They suggested that the impulsive variation of the vertical magnetic field component 
directly indicates the tsunami wave height and arrival time at the station, while the impulsive variation of the horizontal magnetic components indicates the tsunami-propagation direction. They determined the tsunami source $\sim 100 \mathrm{~km}$ northeast from the main rupture area and using joint analyses of the observed magnetic variations and offshore sea-level data verified this source location and that the tsunami origin time was about $1 \mathrm{~min}$ after the EQ origin time. In addition, they suggested that the magnetic field variation and the sea level change indicate that the source area was elongated in the trench direction and had a narrow width.

Zhang et al. [52] reported the observation of Tohoku tsunami-induced EM signals, recorded by a small array of ocean bottom electro-magnetometers consisting of four stations in the northwestern Pacific Ocean. They used several data analysis methods to estimate tsunami parameters.

The wave height was estimated from the observed magnetic and electric fields, while the propagation direction the tsunami was estimated by applying analysis methods for an array and a single station. A related three-dimensional simulation study was published by Zhang et al. [53] concerning the Tohoku tsunami-induced EM signals detected by seafloor magneto telluric stations. Their simulation results were in agreement with both ground-based and sea-bottom magnetic observations, while they found that the field of the primary toroidal magnetic mode can be effective for seafloor observations but only when the seafloor is highly conductive.

\section{Conclusion}

From this short review it is obvious that a great variety of EM phenomena appeared before and after the Tohoku EQ and the associated tsunami. Some of them have been attributed to the EQ preparation processes and have been proposed as possible EQ precursors, others have been associated to the ground/sea level motions due to seismic motion and others have been credited to the tsunami that followed this mega EQ. All of the up to now published articles, elucidate different aspects of these phenomena and contribute to better understanding of their sources, their interactions, as well as efficient ways to observe and discriminate them. Future development of the multidisciplinary field of EM phenomena related to EQs and tsunamis may increase our efficiency in predicting these natural hazards in order to avoid or minimize disasters.

\section{Acknowledgement}

Two of the authors (S.M.P. \& M.H.) would like to express their gratitude to the Matsumae International Foundation for partly supporting this research by providing S.M.P. a 4-month research fellowship [Gno: 17G06] for visiting Hayakawa Institute of Seismo Electromagnetics Co. Ltd.

\section{References}

1. Mori N, Takahashi T, Yasuda T, Yanagisawa H (2011) Survey of 2011 Tohoku earthquake tsunami inundation and run-up. Geophys Res Lett 38(7): L00G14
2. Fujii Y, Satake K, Sakai S, Shinohara M, Kanazawa T, et al. (2011) Tsunami source of the 2011 off the Pacific coast of Tohoku Earthquake. Earth Planets Space 63: 55.

3. The National Police Agency (2016) Damage situation and police countermeasures associated with 2011 Tohoku district - off the Pacific Ocean earthquake.

4. Kazama M, Noda T (2012) Damage statistics (Summary of the 2011 off the Pacific Coast of Tohoku Earthquake damage). Soils and Foundations 52(5): 780-792.

5. Earth, Planets and Space (2011) First Results of the 2011 off the Pacific Coast of Tohoku Earthquake. Earth Planets Space 63(7): 511-902.

6. Earth, Planets and Space (2012) The 2011 Tohoku Earthquake. Earth Planets Space 64(12): 1059-1308.

7. Bulletin of the Seismological Society of America (2013) Introduction to the Special Issue on the 2011 Tohoku Earthquake and Tsunami. Bull Seism Soc America 103(2B): 1165-1627.

8. Science (2013) Special: The Tohoku-Oki Earthquake, Science, Japan.

9. Okada N, Ye T, Kajitani Y, Shi P, Hirokazu Tatano (2011) The 2011 eastern Japan great earthquake disaster: Overview and comments. Int J Disast Risk Sci 2(1): 34-42.

10. Tajima F, Mori J, Kennett BLN (2013) A review of the 2011 Tohoku-Oki earthquake (Mw 9.0): Large-scale rupture across heterogeneous plate coupling. Tectonophysics 586: 15-34.

11. Nagao T, Orihara Y, Kamogawa M (2014) Precursory phenomena possibly related to the 2011 M9.0 off the Pacific coast of Tohoku earthquake. J Disast Res 9(3): 303-310.

12. Sato S (2015) Characteristics of the 2011 Tohoku Tsunami and introduction of two level tsunamis for tsunami disaster mitigation. Proc Jpn Acad Ser B Phys Biol Sci 91(6): 262-272.

13. Liu JY, Chen $\mathrm{CH}$, Lin $\mathrm{CH}$, Tsai HF, Chen $\mathrm{CH}$, et al. (2011) Ionospheric disturbances triggered by the 11 March 2011 M9.0 Tohoku earthquake. J Geophys Res 116(A06319).

14. Heki K (2011) Ionospheric electron enhancement preceding the 2011 Tohoku-Oki earthquake. Geophys Res Lett 38(17): L17312.

15. Akhoondzadeh M (2012) Anomalous TEC variations associated with the powerful Tohoku earthquake of 11 March 2011. Nat Hazards Earth Syst Sci 12: 1453-1462.

16. Choi BK, Park JU, Lee SJ (2012) Ionospheric anomalies observed over South Korea preceding the Great Tohoku earthquake of 2011. Adv Space Res 50(3): 311-317.

17. Le H, Liu L, Liu JY, Zhao B, Chen Y, et al. (2013) The ionospheric anomalies prior to the M9.0 Tohoku-Oki earthquake. J Asian Earth Sci 62: 476-484.

18. Kakinami Y, Kamogawa M, Tanioka Y, Watanabe S, Riadi Gusman A, et al. (2012) Tsunamigenic ionospheric hole. Geophys Res Lett 39(13): L00G27.

19. Kamogawa M, Kakinami Y (2013) Is an ionospheric electron enhancement preceding the 2011 Tohoku-Oki earthquake a precursor? J Geophys Res Space Phys 118(4): 1751-1754.

20. Heki K, Enomoto Y (2013) Preseismic ionospheric electron enhancements revisited. J Geophys Res Space Physics 118: 6618-6626.

21. Utada H, Shimizu H (2014) Comment on Preseismic ionospheric electron enhancements revisited by K Heki and Y Enomoto. J Geophys Res Space Physics 119(7): 6011-6015.

22. Heki K, Enomoto Y (2014) Reply to comment by K Heki and Y Enomoto on "Preseismic ionospheric electron enhancements revisited". J Geophys Res Space Phys 119(7): 6016-6018. 
23. Kuo CL, Lee LC, Heki K (2015) Preseismic TEC changes for Tohoku-Oki earthquake: Comparisons between simulations and observations. Terr Atmos Ocean Sci 26: 63-72.

24. Occhipinti G, Rolland L, Lognonne P, Watada S (2013) From Sumatra 2004 to Tohoku-Oki 2011: The systematic GPS detection of the ionospheric signature induced by tsunamigenic earthquakes. J Geophys Res Space Phys 118(6): 3626-3636.

25. Shinagawa H, Tsugawa T, Matsumura M, Iyemori T, Saito A, et al. (2013) Two-dimensional simulation of ionospheric variations in the vicinity of the epicenter of the Tohoku-oki earthquake on 11 March 2011. Geophys Res Lett 40(19): 5009-5013.

26. Carter BA, Kellerman AC, Kane TA, Dyson PL, Norman R, et al. (2013) Ionospheric precursors to large earthquakes: A case study of the 2011 Japanese Tohoku Earthquake. J Atmos Solar Terr Phys 102: 290-297.

27. Berngardt OI, Kotovich GV, Mikhailov SY, Podlesnyi AV (2015) Dynamics of vertical ionospheric inhomogeneities over Irkutsk during 06:0006:20UT 11/03/2011 caused by Tohoku earthquake. J Atmos Solar Terr Phys 132: 106-115.

28. Maruyama T, Shinagawa H (2014) Infrasonic sounds excited by seismic waves of the 2011 Tohoku-oki earthquake as visualized in ionograms. J Geophys Res Space Physics 119: 4094-4108.

29. Chum J, Hruska F, Zednik J, Lastovicka J (2012) Ionospheric disturbances (infrasound waves) over the Czech Republic excited by the 2011 Tohoku earthquake. J Geophys Res 117(A08319).

30. Hayakawa M, Hobara Y, Rozhnoi A, Solovieva M, Ohta K, et al. (2012) The ionospheric precursor to the 2011 March 11 earthquake as based on the japan-pacific subionospheric vlf/lf network observation. Telecomm Radio Eng 71(18): 1687-1706.

31. Hayakawa M, Hobara Y, Yasuda Y, Yamaguchi H, Ohta K, et al. (2012) Possible precursor to the March 11,2011, Japan earthquake: ionospheric perturbations as seen by subionospheric very low frequency/low frequency propagation. Ann Geophys 55(1): 95-99.

32. Hayakawa M, Hobara Y, Rozhnoi A, Solovieva M, Ohta K, et al. (2013) The ionospheric precursor to the 2011 March 11 earthquake as based on the Japan-Pacific subionospheric VLF/LF network observation. Terr Atmos Ocean Sci 24: 393-408.

33. Hayakawa M, Rozhnoi A, Solovieva M, Hobara Y, Ohta K, et al. (2013) The lower ionospheric perturbation as a precursor to the 11March 2011 Japan earthquake. Geomatics Natural Hazards and Risk 4(3): 275-287.

34. Mullayarov VA, Argunov VV, Abzaletdinova LM, Kozlov VI (2012) Ionospheric effects of earthquakes in Japan in March 2011 obtained from observations of lightning electromagnetic radio signals. Nat Hazards Earth Syst Sci 12: 3181-3190.

35. Rozhnoi A, Shalimov S, Solovieva M, Levin B, Hayakawa M, et al. (2012) Tsunami-induced phase and amplitude perturbations of subionospheric VLF signals. J Geophys Res 117(A09313).

36. Rozhnoi A, Solovieva M, Hayakawa M, Yamaguchi H, Hobara Y, et al (2014) Tsunami-driven ionospheric perturbations associated with the 2011 Tohokuearthquake as detected by subionospheric VLF signals. Geomatics Natural Hazards and Risk 5(4): 285-292.

37. Ouzounov D, Pulinets S, Romanov A, Tsybulya K, Davidenko D, et al. (2011) Atmosphere-ionosphere response to the M 9 Tohoku earthquake revealed by multi-instrument space-borne and ground observations: Preliminary results. Earthq Sci 24(6): 557-564.
38. Hao YQ, Xiao Z, Zhang DH (2012) Multi-instrument observation on coseismic ionospheric effects after great Tohoku earthquake. J Geophys Res 117(A02305)

39. Utada H, Shimizu H, Ogawa T, Maeda T, Furumura T, et al. (2011) Geomagnetic field changes in response to the 2011 off the Pacific Coast of Tohoku Earthquake and Tsunami. Earth Planet Sci Lett 311(1-2): 1127.

40. Kopytenko Yu A, Ismaguilov VS, Hattori K, Hayakawa M (2012) Anomaly disturbances of the magnetic fields before the strong earthquake in Japan on March 11, 2011. Ann Geophys 55(1): 101-107.

41. Hao YQ, Xiao Z (2013) Teleseismic magnetic effects (TMDs) of 2011 Tohoku earthquake. J Geophys Res Space Physics 118(6): 3914-3923.

42. Ohta K, Izutsu J, Schekotov A (2013) The ULF/ELF electromagnetic radiation before the 11 March 2011 Japanese earthquake. Radio Sci 48(5): 589-596.

43. Xu G, Han P, Huang Q Hattori K, Febriani F, et al. (2013) Anomalous behaviors of geomagnetic diurnal variations prior to the 2011 off the Pacific coast of Tohoku earthquake (Mw9.0). J Asian Earth Sci 77: 59-65.

44. Han P, Hattori K, Xu G, Ashida R, Chen CH, et al. (2015) Further investigations of geomagnetic diurnal variations associated with the 2011 off the Pacific coast of Tohoku earthquake (Mw 9.0). J Asian Earth Sci 114: 321-326

45. Han P, Hattori K, Huang Q, Hirooka S, Yoshino C (2016) Spatiotemporal characteristics of the geomagnetic diurnal variation anomalies prior to the 2011 Tohoku earthquake (Mw 9.0) and the possible coupling of multiple pre-earthquake phenomena. J Asian Earth Sci 129: 13-21.

46. Potirakis SM, Hayakawa M, Schekotov A (2017) Fractal analysis of the ground-recorded ULF magnetic fields prior to the 11 March 2011 Tohoku earthquake (MW=9): discriminating possible earthquake precursors from space-sourced disturbances. Nat Hazards 85(1): 59-86.

47. Hayakawa M, Schekotov A, Potirakis S, Eftaxias K (2015) Criticality features in ULF magnetic fields prior to the 2011 Tohoku earthquake. Proc Jpn Acad Ser B Phys Biol Sci 91(1): 25-30.

48. Contoyiannis Y, Potirakis SM, Eftaxias K, Hayakawa M, Schekotov A (2016) Intermittent criticality revealed in ULF magnetic fields prior to the 11 March 2011 Tohoku earthquake $\left(\mathrm{M}_{\mathrm{w}}=9\right)$. Physica A 452: 19-28.

49. Tatehata H, Ichihara H, Hamano Y (2015) Tsunami-induced magnetic fields detected at Chichijima Island before the arrival of the 2011 Tohoku earthquake tsunami. Earth Planets Space 67: 185.

50. Klausner V, Kherani EA, Muella MT (2016) Near and far-field tsunamigenic effects on the $\mathrm{Z}$ component of the geomagnetic field during the Japanese event, 2011. J Geophys. Res Space Physics 121(2): 1772-1779.

51. Ichihara H, Hamano Y, Baba K, Kasaya T (2013) Tsunami source of the 2011 Tohoku earthquake detected by an ocean-bottom magnetometer Earth Planet Sci Lett 382: 117-124.

52. Zhang L, Baba K, Liang P, Shimizu H, Utada H (2014) The 2011 Tohoku Tsunami observed by an array of ocean bottom electro magnetometers. Geophys Res Lett 41: 4937-4944.

53. Zhang L, Utada H, Shimizu H, Baba, Maeda T (2014) Three-dimensional simulation of the electromagnetic fields induced by the 2011 Tohoku tsunami. J Geophys Res Solid Earth 119(1): 150-168. 